\title{
Designing a High-Speed Press with a Six-Bar Linkage Mechanism
}

\author{
Tim Benkert ${ }^{1, a}$, Andreas Krinner ${ }^{2, b}$, Thomas Thümmel ${ }^{2, c}$ \\ and Wolfram Volk ${ }^{1, d}$ \\ ${ }^{1}$ Technische Universität München, Institute of Metal Forming and Casting, Wal- \\ ther-Meißner-Straße 4, 85748 Garching, Germany \\ ${ }^{2}$ Technische Universität München, Institute of Applied Mechanics, Boltzmannstraße 15, \\ 85748 Garching, Germany \\ atim.benkert@utg.de, bandreas.krinner@tum.de, 'cthuemmel@tum.de, dwolfram.volk@utg.de
}

Keywords: Design method, Mechanism, High-speed press

\begin{abstract}
This paper describes the design process of a high-speed cutting press with a linkage mechanism in its drive train. The whole process is carried out for a virtual prototype. The kinematic and dynamic properties of the six-bar linkage mechanism are optimised regarding boundary conditions coming from the production process and kinematic requirements. Using a rigid body model, the geometric dimensions and inertia parameters of the links of the mechanism can be determined. A finite-element (FE) model is build up to check the parts' durability during work load. A verification of main results is realised on an experimental prototype made from rapid prototyping material.
\end{abstract}

\section{Introduction}

Research on high-speed cutting in the blanking process is motivated by experimental studies, which have shown, that high cutting velocities $(>0.8 \mathrm{~m} / \mathrm{s}$ [1]) lead to changed cutting edge characteristics when blanking metal parts. Rollover, clean shear and burr are reduced while fracture is increased. The surface roughness of the cutting edge's fractured area decreases significantly, as well as blanking forces do [2]. High-speed cutting has no nameable share in mass production of sheet metal products yet, which is among other things due to missing machinery [3]. The term 'high-speed press' is misleading in this context, since it describes the press' ability to run at high stroke rates but does not indicate high ram velocities at operation point. At the moment, no press machine, which can reach such high cutting velocities at high output, is available on the market. In order to realise high-speed cutting on mechanical presses and with it open its way into mass production, a new concept for the presses driving unit design is followed. A toggle lever press' ram way movement shall be inverted. This press type's characteristic ram way movement leads to low ram speeds close to the bottom dead centre (BDC) and high speeds close to the top dead centre (TDC) [3]. Toggle lever presses are driven by six-bar linkage mechanisms which offer a variety of parameters to affect their drive side behaviour [4]. Therefore the press concept described and evaluated in this paper is based on such a mechanism.

The contribution is structured as follows: In the first three sections, the kinematic problem is described and a process for an optimal kinematic and dynamic synthesis of the mechanism is proposed. It is applied to the virtual prototype. An experimental prototype scaled 1:2 to the virtual one is then 3D printed in a rapid prototyping process. It will be investigated experimentally and virtually. The results show a good agreement between experiment and simulation and therefore verify the whole design process. Lastly, a summary and conclusion are given.

\section{Kinematic Problem and Mechanism Concept}

Firstly, requirements for the virtual prototype's design are described. The designed press should be able to cut aluminium sheets of $1 \mathrm{~mm}$ thickness $(D=1 \mathrm{~mm})$ with a process force of $10 \mathrm{kN}$. 
The kinematic problem of a press machine can be well addressed by its ram way curves $s(\varphi)$, see Fig. 1. At the same time, press characteristic terms and parameters can be defined. In addition, the time derivatives of the ram way curves (velocities and accelerations) can be helpful for the specification. The upper and lower limitations of the ram way are called top dead centre (TDC) and bottom dead centre (BDC), respectively. The ram way is the distance between these two points and should not exceed $20 \mathrm{~mm}$, here.

Essential for high-speed cutting is the velocity, which is proportional to the slope of the tangent, at operation point (OP), which is located $2 \mathrm{~mm}\left(=2^{*} D\right)$ above the BDC in order to cut a sheet of thickness $D=1 \mathrm{~mm}$. As the sheet will break shortly after striking of the cutting tool, there is enough space to BDC left for slowing down the ram.

In the distance of twice the sheet thickness above the operation point (OP) there are the handling points (HP). Above these points there is time for handling the sheet, e.g. for feed motion.

Besides the requirements for the ram way curve $s(\varphi)$, there is also a need to fulfil demands of process and mass production. The real cutting velocity at operation point (OP) and the handling time depend on the press' clock frequency. It should be between 400 to 1000 strokes/min, which corresponds to 150 to $60 \mathrm{~ms}$ per stroke.

A classical slider crank mechanism always delivers a nearly cosines-shaped curve for the ram way (dashed line in Fig. 1). The advantage would be the simple and robust structure of the mechanism with only three movable links (crank, connecting rod, ram), but the demanded velocities at operation point (OP) for high-speed cutting could only be achieved at technical not feasible rotating speeds. Therefore, the more complex six-bar linkage mechanism with rest is chosen. Fig. 2 shows the kinematic scheme and defines further used parameters. The constant rotation of the crank (2) causes via the connecting rod (5) and the coupler (3), which is connected by the rocker (4) to the casing (1), a nonlinear ram way curve with high velocity at the OP and a rest phase.

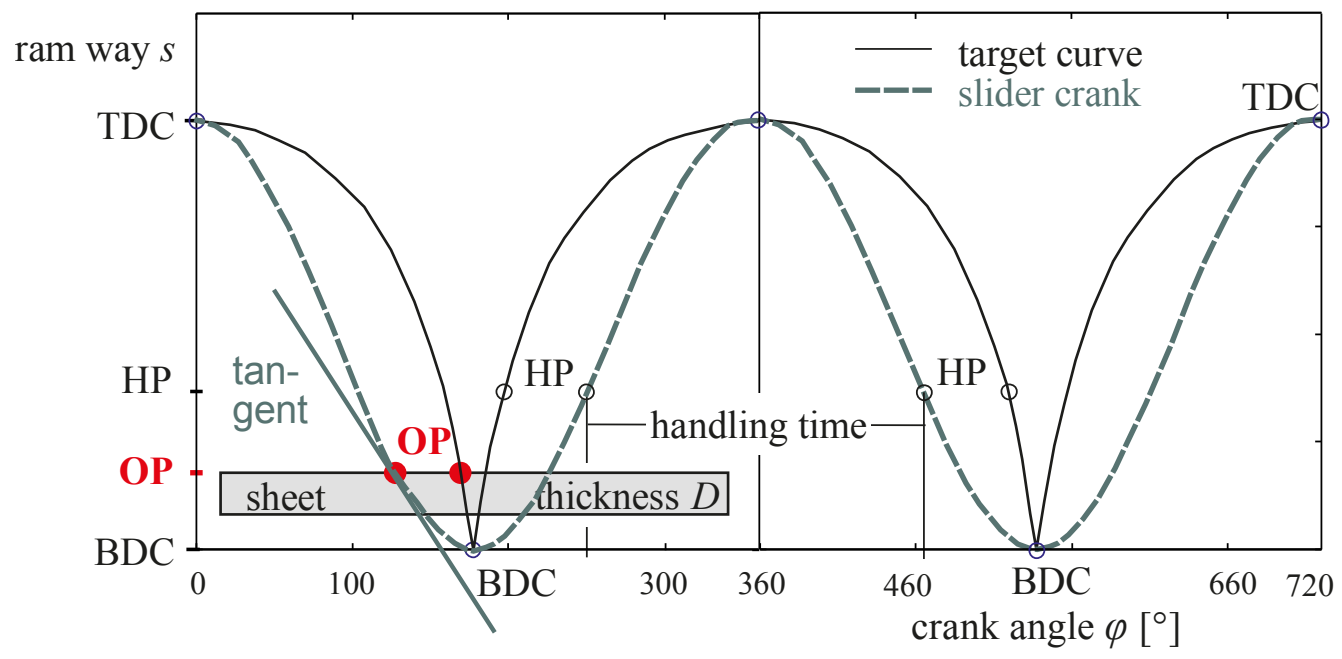

Figure 1: Kinematic problem in form of ram way curve

\section{Kinematic Synthesis}

After having defined the mechanism's concept and parametrization in the previous section, this one aims to determine concrete parameters under consideration of specified process requirements. In addition, criteria for the practical design have to be guaranteed: These are capability of revolution, compliance of available space and maximal stroke way as well as avoiding acute transmission angles. Collision aspects of movable links or bearing diameters are not yet considered in this stage.

Since the mechanism's kinematics is nonlinear due to its geometric dimensions, a mathematical optimization problem for determining the parameters is set up. The optimization is done in Matlab, using the algorithm 'fmincon', where equality as well as inequality conditions can be considered. Hence, the kinematic and kinetic equations of the specific mechanism are implemented in Matlab. 
Additionally the software tool WinDAM 2.7 [5] is used for verification, visualization and animation of results.
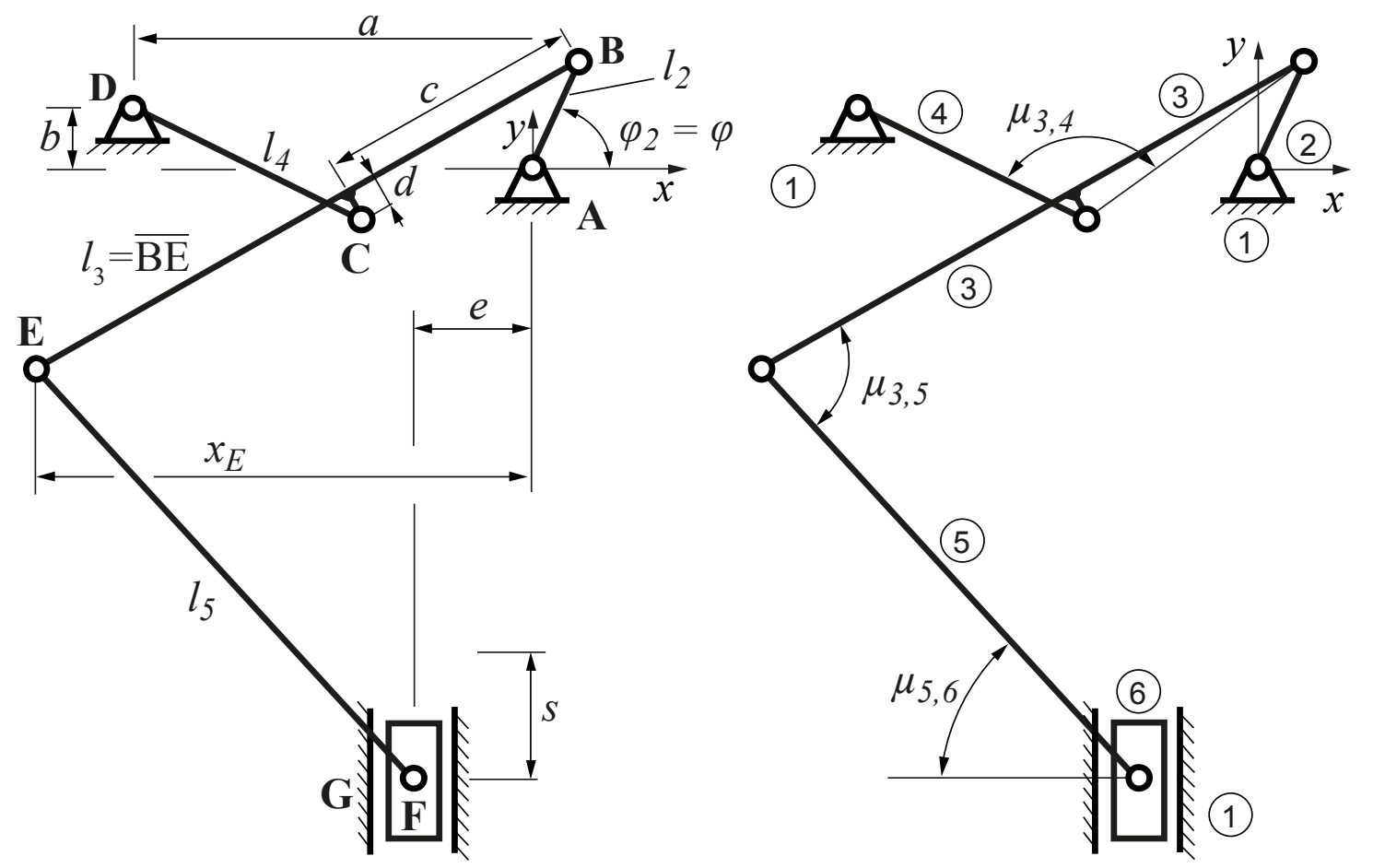

Figure 2: Kinematic scheme of the six-bar linkage mechanism with rest

A detailed description of the mathematical optimization can be found in [6]. Here, the main properties are stated only: The used objective function is minimal rotation speed. Therefore the cutting velocity at operation point is severely prescribed at $\mathrm{v}_{\mathrm{OP}}=2 \mathrm{~m} / \mathrm{s}$. All other process and design conditions are formulated as constraints. The optimization is repeated several times and with various objective functions and constraints. The individual parameters and their boundaries are varied step by step. In advance, parameter studies are executed in order to get a feeling for the sensitivity of different parameters on the objective function and on the constraints.

After various iterations with evaluation of plausibility, the parameters are determined like in Fig. 3. The scaled scheme can be seen in the middle of the picture. Lastly, the choice of the parameters $d=0, c=l_{4}=l_{3} / 2$ (see Fig. 2) shall be emphasised, which ensure a symmetric ram way curve (Fig. 3 right) with minimal accelerations. The stroke curve has four positions of rest and little reversal points between BDC and TDC.

\begin{tabular}{l|clc} 
param. & value & param. & value \\
$\mathrm{a}[\mathrm{mm}]$ & 32.7 & $\mathrm{v}_{\mathrm{OP}}[\mathrm{m} / \mathrm{s}]$ & 2 \\
$\mathrm{~b}[\mathrm{~mm}]$ & 0 & ram way $[\mathrm{mm}]$ & 20 \\
$\mathrm{l}_{2}[\mathrm{~mm}]$ & 18.9 & $\mathrm{a}_{\max }\left[\mathrm{m} / \mathrm{s}^{2}\right]$ & 777 \\
$\mathrm{l}_{3}[\mathrm{~mm}]$ & 80 & $\mu_{3,4, \min }\left[^{\circ}\right]$ & 20 \\
$\mathrm{c}[\mathrm{mm}]$ & 40 & $\mu_{5,6, \min }\left[^{\circ}\right]$ & 30 \\
$\mathrm{~d}[\mathrm{~mm}]$ & 0 & $\Omega_{\min }[\mathrm{rpm}]$ & 625 \\
$1_{4}[\mathrm{~mm}]$ & 40 & & \\
$1_{5}[\mathrm{~mm}]$ & 400 & & \\
$\mathrm{e}[\mathrm{mm}]$ & 32.7 & &
\end{tabular}
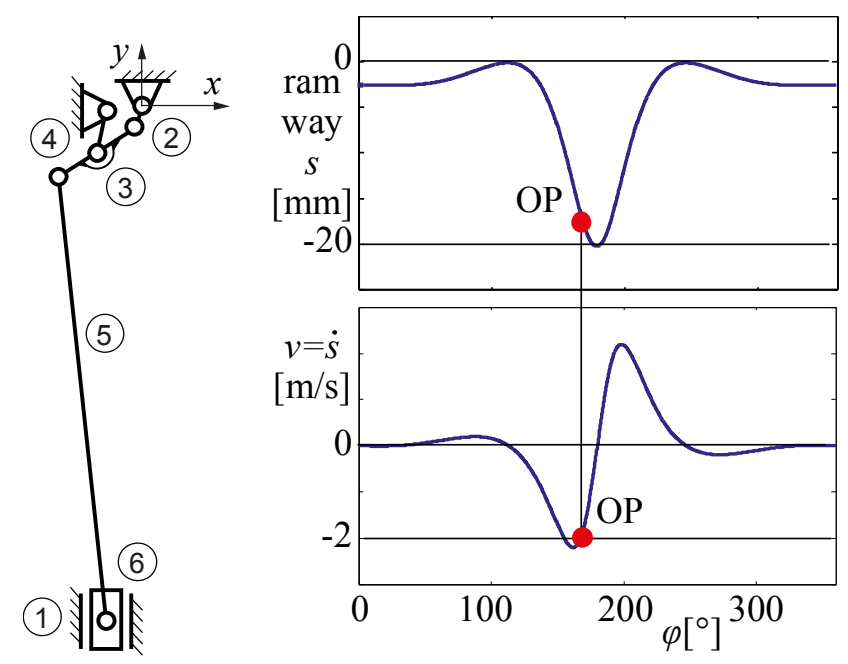

Figure 3: Results of kinematic synthesis of the press with six-bar linkage mechanism 


\section{Dynamics of Machinery Aspects}

In this section the inertia parameters of the links are determined, while considering and possibly iteratively adapting the geometric parameters of the previous section. The aim is to keep dynamic forces as low as possible. The main focus is placed on the balancing of the fundamental force in vertical direction. Resulting horizontal forces can be easily compensated by a symmetric arrangement of two identical mechanisms, see Fig. 5.

For the mass balancing of the fundamental force in y-direction, three different types of additional balancing mechanism (Fig. 4 left) are analysed (partial mass balancing). A complete mass balancing or a balancing without additional linkages cannot be achieved within the design limits. The used optimization approach is the same as in the previous section, with the difference of optimizing the geometric and inertia parameters of the mass balancing mechanism now. For more details it is referred to [6].

While type 1 aims at balancing inertia forces of all linkages, type 2 and 3 try to compensate the ram's dynamic force only. From a practical point of view, the latter issue seems to be sufficient, as the resulting force $\mathrm{F}_{\mathrm{y}}$ can be reduced by nearly $98 \%$ with the mechanism of type 3 , as the upper diagram in Fig. 4 right shows. The lower diagram shows, that as a consequence of adding a mass balancing mechanism the driving moment $\mathrm{M}_{\mathrm{An}}$ increases. This drawback can be remedied by a properly designed flywheel [4].

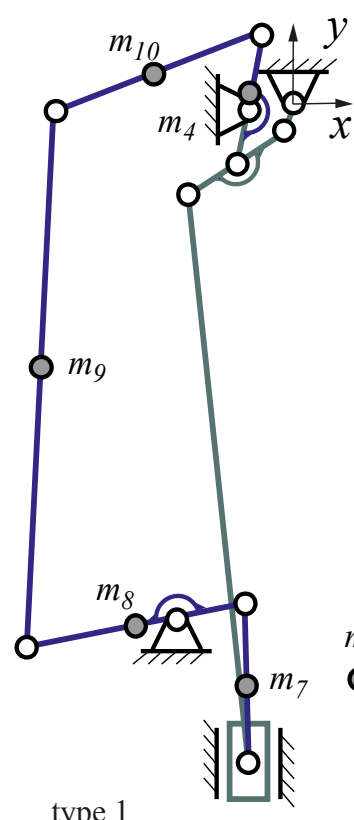

type 1

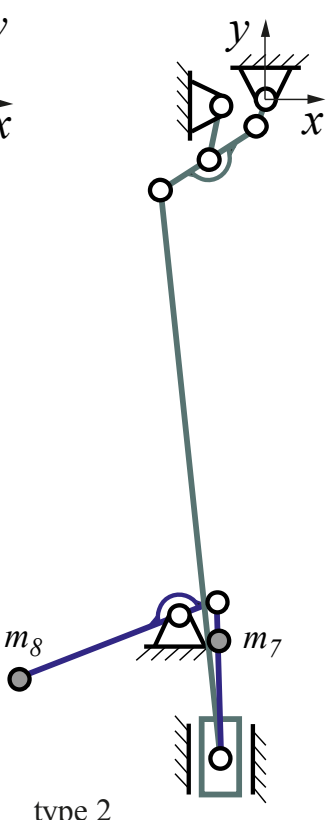

type 2

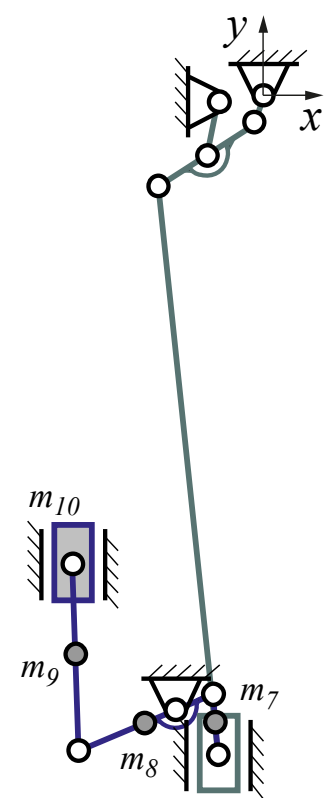

type 3
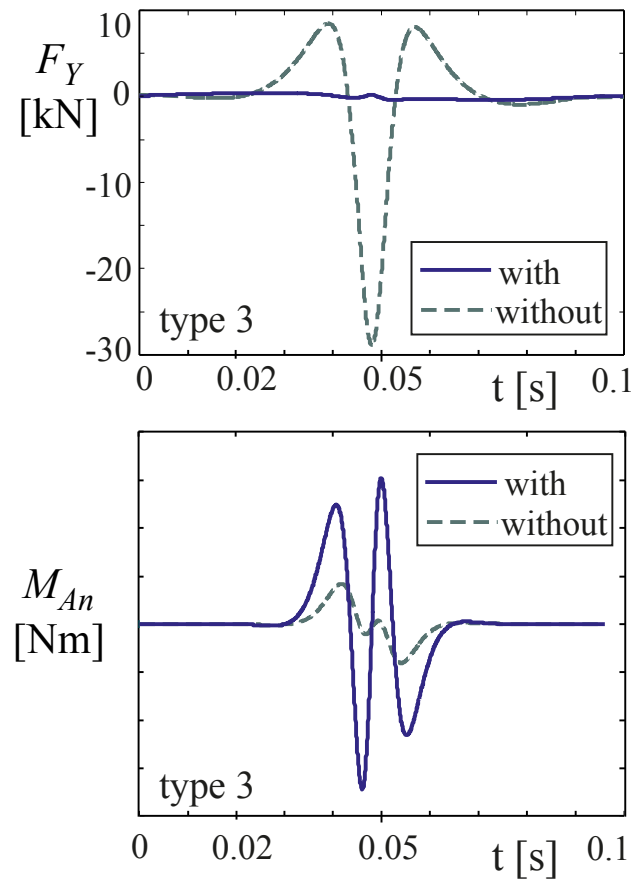

Figure 4: Different types of mass balancing systems, reaction forces and needed drive torque for mass balancing system type 3

\section{Experimental Prototype}

This section outlines the practical design of the experimental setup and shows how to put it into operation. The model is referred to as an experimental prototype and is pictured in Fig. 5. In addition, the measuring technique needed for the experimental validation is described.

The experimental prototype's aim is to demonstrate the feasibility of the mechanism concept. It is based on the virtual prototype (Fig. 3) but scaled down by the factor two. Due to lower production costs of the parts, these are printed within a rapid prototyping process. The parts are sliced into layers of 150 microns thickness and the data transferred to a laser sintering device. This device uses fine-grained polymethylmethacrylate (PMMA) to build the product. After the printing process is 
finished, the parts are infiltrated with epoxy resin to increase their yield strength. While the bars for the mechanism are made from PMMA, the press ram consists of aluminium. Sheet metal aluminium is used for front faces and the columns on each corner of the press prototype are formed by angle profiles. The front faces supply flanges for further components of the drive train.

The press' fundament - in the following referred to as platform - is made from extruded aluminium sheath and sits on four spiral springs (indicated in Fig. 5). This platform holds the electric engine to drive the prototype and the sensors to collect data during operation. The spiral springs allow the platform to swing even under small loads which is necessary to get any signal at all.

Measurement data are generated by one path sensor and five acceleration sensors. Sensor 1 in Fig. 5 is the path sensor, which delivers the ram way. It is mounted on one of the press frame's front faces and is pointing down towards the ram. The second sensor is the acceleration sensor attached to the ram which measures the ram acceleration. Sensors 3 to 6 are mounted on the platform's corners over the four spiral springs. Their signals are averaged and used as a value for the platform acceleration. All six sensors are time synchronised.

Two different test series are run with the press operating at $120 \mathrm{rpm}$. The first series is done with the mass balancing system, while for the second one the mass balancing system is decoupled. Thereby the effect of the mass balancing system shall be verified.

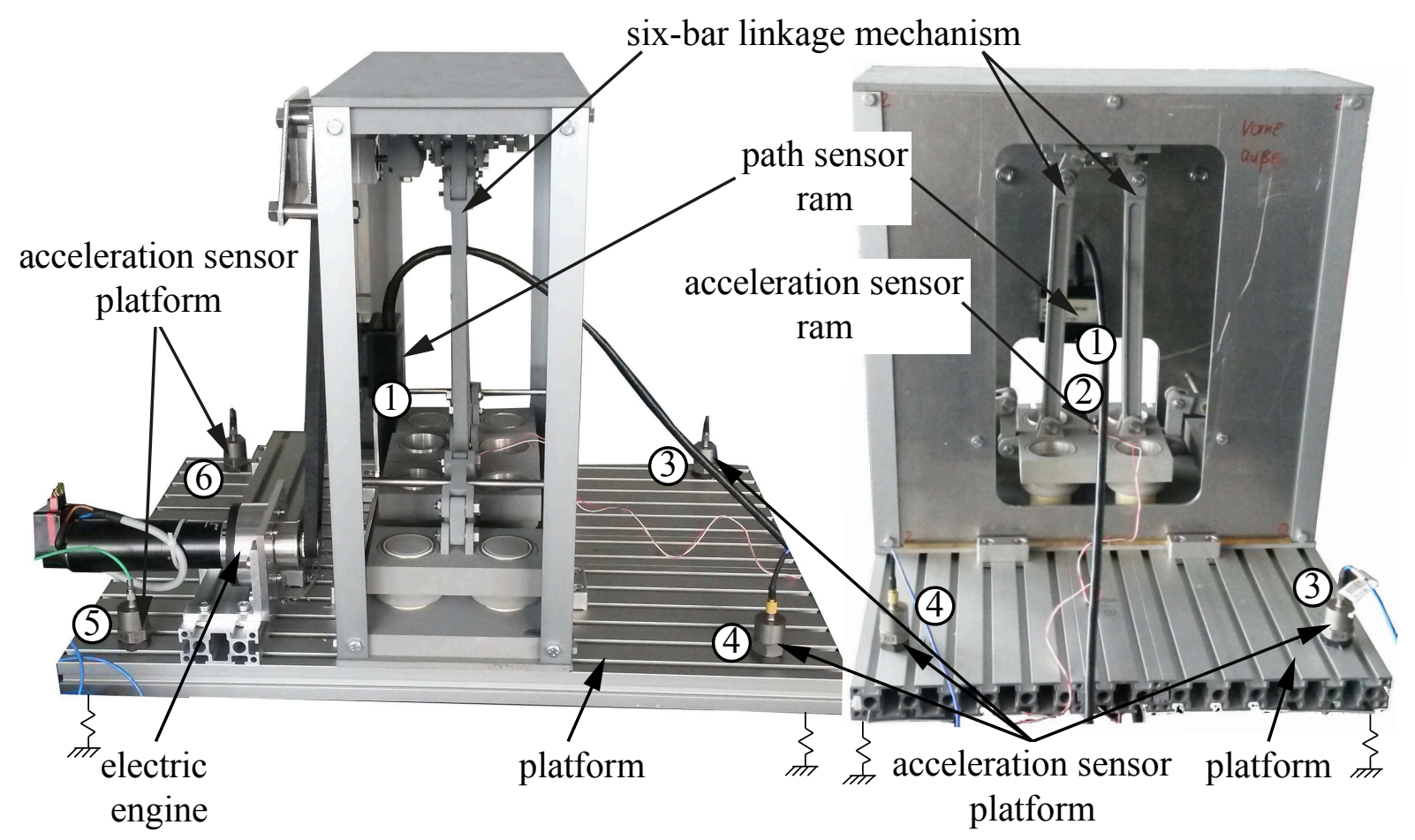

Figure 5: Experimental setup for the verification of simulation results

\section{FE Simulation of the Experimental Prototype}

In this section, the simulation model of the experimental prototype is explained. The model's main parts and the applied boundary conditions are described.

The press prototype is modelled in Ansys Workbench 15 as a quarter model. Due to reduction of simulation time, the press frame, the platform and the drivetrain are not considered. All parts with moving centre of mass are included in the simulation model, even the connecting elements (bolts) which represent a significant part of the mechanism's total mass. Bearings are not modelled as own parts, instead the connection bolt's density is raised to take their mass into account.

Following boundary conditions are applied to the model. First of all, a symmetry condition is applied to all surfaces, which appear after quartering the model the rocker (No. 2 in Fig. 6) is not cut, no symmetry condition is applied here. In exchange two symmetry conditions are applied to the ram 
(No. 10 in Fig. 6) since it is cut by both symmetry planes. The second boundary condition takes into account the mechanism's mounting points in the press frame. These are applied as cinematic constraints to the press ram, the rocker and the crank. The ram is allowed to move vertically only, while the movement of rocker and crank is restricted to rotation around their upper hole (see Fig. 6).

Due to the fact, that it is a nonlinear system, for calculation an algorithm based on Newton's method is used. Results are calculated within two steps to avoid problems when the computation starts. During step one the mechanism is accelerated linearly to its nominal rotation speed using a kinematic constraint on the crank. Within the second step steady state conditions are simulated. Both steps take one second and a time step width of $0.5 \mathrm{~ms}$ is used which adds to 4000 time steps in total.

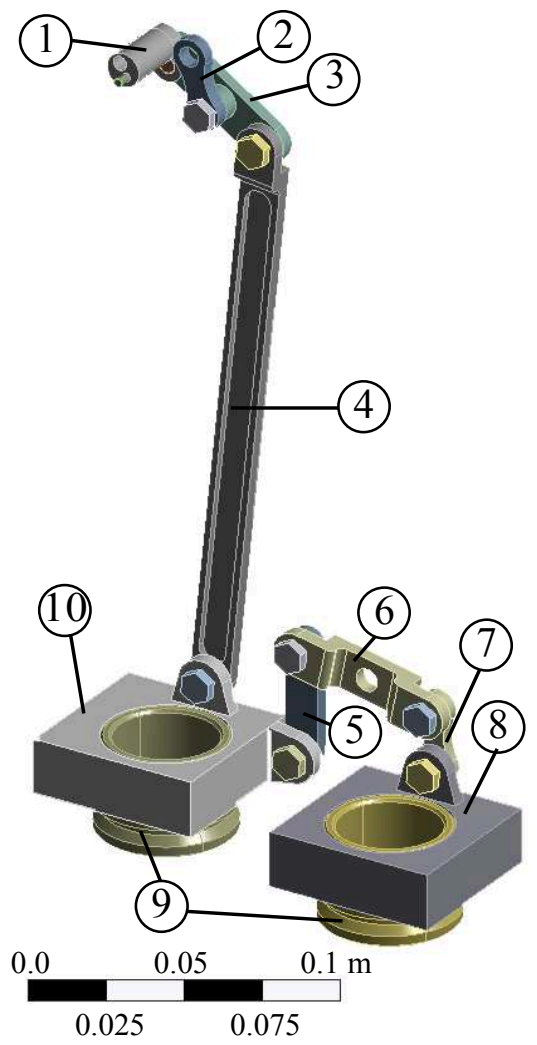

\begin{tabular}{|l|l|}
\hline No. & Name \\
\hline 1 & crank \\
\hline 2 & rocker \\
\hline 3 & coupler \\
\hline 4 & connecting rod \\
\hline 5 & driver mbs \\
\hline 6 & coupler mbs \\
\hline 7 & drive side mbs \\
\hline 8 & ram mbs \\
\hline 9 & guide bushing \\
\hline 10 & ram \\
\hline mbs & $\begin{array}{l}\text { mass balancing } \\
\text { system }\end{array}$ \\
\hline
\end{tabular}

Figure 6: Simulation model in Ansys Workbench 15, according to [7]

\section{Results of Verification}

This section will show the experimental as well as the corresponding simulation results and compare them to each other. It shows the feasibility of the mechanism concept together with its design process for a high speed press.

The diagrams in Fig. 7 show the ram way (left) and the ram acceleration (right). As it can be seen, the measured ram way and the calculated one fit quite well when tolerances (e.g. clearance in bearings) of the experimental prototype are taken into account. For the ram acceleration large deviations are recognisable only around a crank angle of $210^{\circ}$. This is due to the superimposed oscillation of the platform that has one of its eigenfrequencies close to the operation point. Filtering it is therefore not possible and the shown deviations are caused.

In Fig. 8 the reaction force on the experimental prototype's platform is shown. The left side illustrates the forces without using the mass balancing system and the right the forces when the prototype is run with the mass balancing system in operation. To match calculated and measured data it is necessary to work further on the computed results since the simulation neglects the platform and the spiral springs it sits on (see section 'simulation'). The platform is modelled in Matlab as a one mass oscillator which is excited by the reaction forces coming from Ansys. To calibrate the damping fac- 
tor - the last unknown - the measurement of the reaction forces without mass balancing system is used. The calibrated model is then run again, this time excited by the calculated reaction forces with the mass balancing system. As the results match well (see Fig. 8 right) the simulation is regarded as delivering correct forecasts.
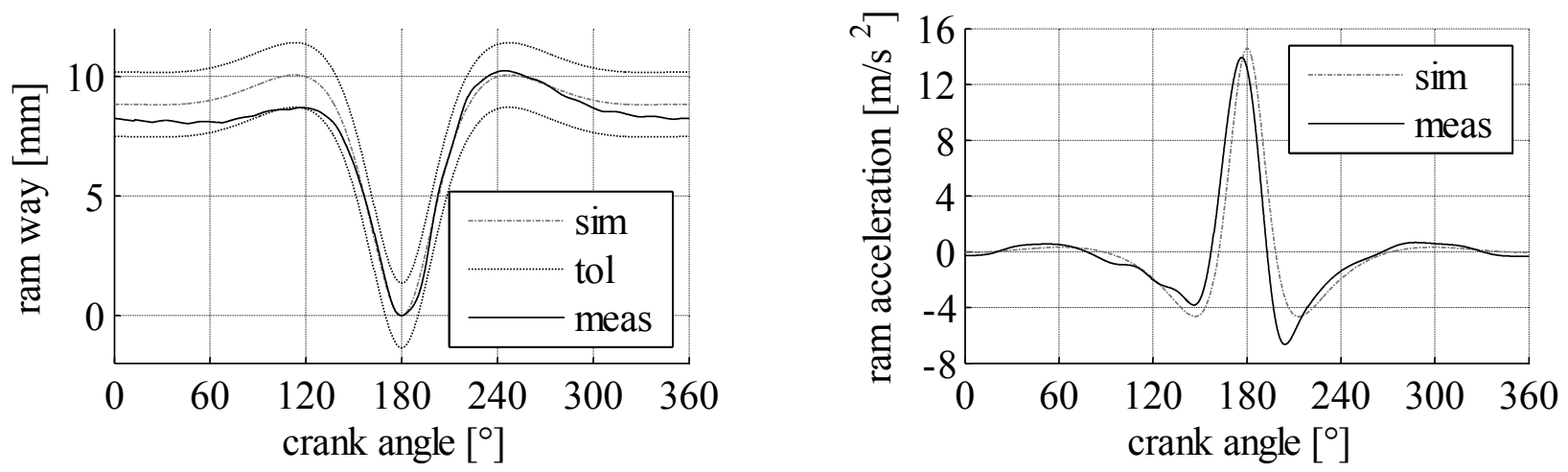

Figure 7: left: $\quad$ ram way on crank angle right: ram acceleration on crank angle $\operatorname{sim}=$ simulation, tol $=$ tolerance corridor, meas $=$ measurement
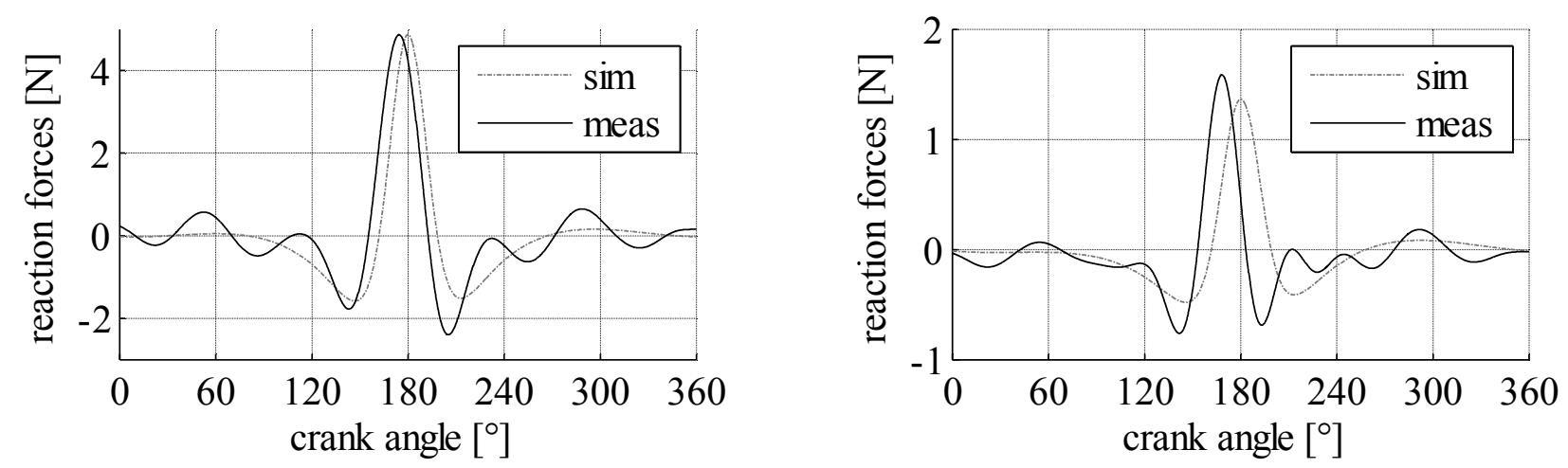

Figure 8: Reaction forces on the platform at $120 \mathrm{rpm}$ on crank angle left: without mass balancing system right: with mass balancing system $\operatorname{sim}=$ simulation, meas $=$ measurement

The mass balancing system's efficiency has been validated as well. Reaction forces on the platform were reduced significantly with the mass balancing system in operation. The simulation delivers fundament forces reduced to $28 \%$, the measurements show a reduction to $33 \%$ [7].

Summarised, the computed results have been verified by the experiments.

\section{Summary}

The results show that high-speed cutting on mechanical high-speed presses is feasible and thereby high output can be generated. Furthermore a procedure for the mechanical layout, design, simulation and experimental verification of a press prototype is developed. The procedure is successfully proved on an experimental setup of a 3D-printed prototype.

Further important conclusions from the project are as follows. The six-bar linkage mechanism is well suitable as driving unit of mechanical presses for high-speed cutting. In comparison to a classical slider crank mechanism it allows the designer to fulfil the complex kinematic requirements for high-speed cutting at adequate rotation speeds. The resulting higher dynamic loads can still be handled. In addition, the mechanism is well documented within VDI guidelines. 
Due to the complexity of the six-bar linkage mechanism, it has to be constantly checked during the design process, if there are any design limitations that make building the press impossible. These limitations can result from bearing sizes necessary to transfer the high operation loads from one bar to the other or from part dimensions resulting from operation loads.

A further result, which has not been mentioned yet is, that a press which is designed to be used for high-speed cutting cannot be geometrically scaled. This is due to the invariant cutting velocity coming from the process. For every combination of press force, size and rotations per minute one point of the ram way variation in time is fixed. Every change to one of the named parameters therefore requires the design procedure of the mechanism to be run again.

\section{Acknowledgement}

The research project "Mechanische Schnellläuferpresse mit Koppelrastgetriebe" (Mechanical High-Speed Press with Linkage Mechanism) whose results are summarised in this paper was kindly supported by the German Federation of Industrial Research Associations (AiF) through the European Research Association for Sheet Metal Working (EFB).

\section{References}

[1] M. Schüßler, Hochgeschwindigkeits-Scherschneiden im geschlossenen Schnitt zur Verbesserung der Schnittteilequalität, IFF-IFU, Darmstadt, 1990.

[2] W.-G. Drossel, T. Barthel, T. Kopp, W. Volk, Entwicklung kalkulatorischer Kenngrößen zur Gestaltung von Scherschneidprozessen und Bewertung der Bauteilqualität bei Anwendung hoher Schneidgeschwindigkeiten, first ed., European Research Association for Sheet Metal Working (EFB), 2012.

[3] H. Hoffmann, R. Neugebauer, G. Spur, Handbuch Umformen, first ed., Carl Hanser Verlag, München, 2012.

[4] H. Dresig., F. Holzweissig, Dynamics of machinery: theory and applications, Springer Verlag, Berlin, Heidelberg, 2010.

[5] K. Kaltofen, WinDAM - Dynamic analysis of planar mechanism, software tool on http://kaltofen-engineering.de/index.php/Software [2014-02-14].

[6] T. Benkert, T. Thümmel, A. Krinner, Entwurf eines Pressenantriebes zum Hochgeschwindigkeitsscherschneiden, 17. VDI Getriebetagung Bewegungstechnik 2014, VDI Verlag $\mathrm{GmbH}, 2014$.

[7] T. Benkert, M. A. Kleser, Nummerische Simulation einer Schnellläuferpresse unter Verwendung der FEM, mediaTUM, München, 2015 